\title{
A study of cervical length measured ultrasonographically in prediction of preterm delivery
}

\author{
Verma S. ${ }^{1}$, Meena B. S. ${ }^{2}$, Pooja ${ }^{3}$, Sehra R. N. ${ }^{4}$ \\ ${ }^{1}$ Dr Suniti Verma, Professor, ${ }^{2}$ Dr Bhanwar Singh Meena, Senior Professor, ${ }^{3}$ Dr Pooja, Senior Resident, ${ }^{4}$ Dr Ram Narain \\ Sehra, Professor, all authors are affiliated with Department of Gyne \& Obst, S. M. S. Medical College, Jaipur, Rajasthan.
}

Address for Correspondence: Dr Ram Narain Sehra, MD, Professor, Department of Pediatrics, SMS Medical College, Jaipur, Rajasthan, e-mail- rnsehra@gmail.com

\begin{abstract}
Introduction- Cervical length appears to be an efficient test for predicting preterm birth. Transvaginal sonography (TVS) is the preferred route for cervical assessment to identify women at increased risk of spontaneous preterm birth and may be offered to women at increased risk of preterm birth. Methods- This was prospective observational study conducted in Obstetrics and Gynecology department of SMS Medical college, Jaipur, Rajasthan, Indiafrom August 2015 to July 2016. Out of obstetric cases attending antenatal OPD, cases of singleton pregnancies were selected at random. In this study all the participants were divided into 2 groups: Each group include 100 patients. Every participant underwent a transvaginal sonography (TVS), using probe of 5 to $7.5 \mathrm{MHz}$, measuring cervical length. Results- About 39 women in control group and 36 women in study group were primigravida, remaining were multigravida. History of preterm labour was present in 27 women in study group and 28 women in control group. Cervical length measurement was 21-26 mm in 30 (30\%) women and among them $12(44.44 \%)$ delivered preterm. Mean birth weight was $1.75 \pm 0.04$ in control group and $1.75 \pm 0.06$ in study group in which cervical length was between $21-26 \mathrm{~mm}$. In our study in study group revealed Prevalence $-27 \%$, Positive predictive value $-52.10 \%$, Negative predictive value $-88.70 \%$, Sensitivity $-81.48 \%$, Specificity $-75.34 \%$. Conclusion- We found that TVS had good sensitivity, specificity, predictive value in both group. Thus measurement of cervical length by TVS can be used to predict increase risk of preterm delivery cases with threatened preterm labor.
\end{abstract}

Keywords - Cervical length, Multigravida, Preterm delivery, Transvaginal ultrasonography.

\section{Introduction}

Preterm delivery is the leading cause of neonatal mortality and morbidity [1]. Although many predictors for preterm delivery have been proposed, complete prediction and prevention have not yet been established [2]. Cervical length appears to be an efficient test for predicting preterm birth; it has been found to be the best single predictor of preterm birth $<34$ weeks in asymptomatic women, with the risk of preterm delivery increasing dramatically for lengths $<15 \mathrm{~mm}[3,4]$. Transvaginal sonography (TVS) is the preferred route for cervical assessment to identify women at increased risk of spontaneous preterm birth and may be offered to women at increased risk of preterm birth. Also, it can be used to assess the risk of preterm birth in women with a history of spontaneous preterm birth and to differentiate those at higher and lower risk of preterm delivery [5]. Cervical length is an independent predictor of preterm delivery in women with preterm labor [6].

Manuscript received: $10^{\text {th }}$ October 2017

Reviewed: $20^{\text {th }}$ October 2017

Author Corrected: $28^{\text {th }}$ October 2017

Accepted for Publication: $2^{\text {nd }}$ November 2017

Obsgyne Review: Journal of Obstetrics and Gynecology

\section{Aims and Objective}

1. To compare length of cervical canal in patient with normal pregnancy and patient with high risk for preterm labor.

2. To study the relation of cervical length with preterm delivery and baby outcome.

\section{Material and Methods}

Study design- This was prospective observational study conducted in Obstetrics and Gynecology department of SMS Medical college at Mahila Chikitsalya, Sanganeri Gate, Jaipur, Rajasthan, Indiafrom August 2015 to July 2016. Out of obstetric cases attending antenatal OPD, cases of singleton pregnancies were selected at random after thorough history taking and meticulous clinical examination. Prior to commencement of first examination, informed consent was taken and patient was explained about the study. This study was approved by research ethical committee.

Available online at : www.medresearch.in 38 | P a g e 


\section{Inclusion Criteria}

- Women with gestational age $\geq 30$ to $\leq 32 \mathrm{wk}$.

- Singleton gestation.

- Women with intact amniotic membrane.

- Women with complain of threatened preterm labor, defined as occurrence of uterine contraction have no effacement or dilatation of cervix by digital examination.

\section{Exclusion Criteria}

- Pregnant women with other complicating factor which are indicationfor induced preterm delivery such as

(a) Preeclamsia

(b) Pregnancy with severe IUGR

(c) Pregnancy with $\mathrm{RH}$ isoimmunization

- Cervical incompetence

- Multiple gestation

- Low lying placenta

- History of first trimester bleeding

- Presence of uterine malformation and leiomyoma.

In this study all the participants were divided into 2 groups : Each group included 100 patients. Both of the group were statistically matched for age,socioeconomic status and duration of pregnancy.

Control Group: This group include

1. $\geq 30-\leq 32$ week of singleton pregnancy

2. No risk factors for preterm labor

Study Group: This is target group, include

1. Patient with gestation age $\geq 30-\leq 32$ week of pregnancy
2. Patient with risk for preterm labor i.e. patient with threatened preterm labor.

Study methods- Every participant underwent a transvaginal sonography (TVS), using probe of 5 to 7.5 $\mathrm{MHz}$, measuring cervical length. Every scan was done by same person to reduce the interobserver variability and improve reproducibility of cervical measurements. Scan was performed in patient in semi supine position, buttock slightly elevated. Before proceeding to transvaginal ultrasound patients were asked to empty the bladder. With the patient in lithotomy position vaginal probe was introduced into vagina and the length was measured with the probe placed in anterior fornix of vagina. The appropriate sagittal view of cervix was obtained by simultaneous imaging of external and internal os. External os was identified by its triangular echo density and internal os by its $\mathrm{V}$-shape appearance.

The cervical canal was seen as a translucent line connecting these two points. The distance between the external and internal os was taken as cervical length. Three measurements were obtained and shortest technically the best measurement in the absence of uterine contraction was recorded. Every patient was managed according to risk factor and followed throughout gestation. The ultimate outcome of pregnancy was noted in term of delivery before 37 weeks or after it.

Statistical analysis- All the data were compiled. Mean cervical length was calculated in two groups. In cases of categorical variables counts and percentages were recorded. 'p' value $<0.05$ was considered as significant. Statistical analysis was performed with unpaired ' $t$ ' test and by Chi-Square test. Computer software SPSS 22.0for windows was used for analysis.

\section{Results}

Study was conducted on 200 pregnant women. Among them 100 were those who came with threatened preterm labor and 100 were asymptomatic. About $6 \%$ of pregnant women in both study and control group were under the age of 20 years, $80 \%$ of control group and $81 \%$ of study group were in age group of $20-25$ years, $12 \%$ of control group and $11 \%$ of study group were in age group of 26-30 years and $2 \%$ study and control group were over the age of 30 years.

Maximum number of women (50\%) in control group and $52 \%$ in study group were illiterate followed by those who have received primary level of education, $22 \%$ in control group and $24 \%$ in study group. The patients who received college education were $10 \%$ in control group and $8 \%$ in study group and none of the patients had received professional level of education. About 39 women in control group and 36 women in study group were primigravida, remaining were multigravida. About $4(10.26 \%)$ out of 39 women in primigravida and $14(22.95 \%)$ out of 61 women in multigravida had cervical length $\leq$ $26 \mathrm{~mm}$ in control group. About $11(30.56 \%)$ out of 36 women in primigravida and $27(42.19 \%)$ out of 64 women in multigravida had cervical length $\leq 26 \mathrm{~mm}$ in study group. In control group $18 \%$ and in study group $38 \%$ women had cervical length $\leq 26 \mathrm{~mm}$ that is significant. History of preterm labour was present in 27 women in study group and 28 women in control group. About 20 (74.07\%) out of 27 had cervical length $\leq 26 \mathrm{~mm}$ in study group and 7 (25\%) women in control group had cervical length $\leq 26 \mathrm{~mm}$ as it is known that preterm labour is more common in patient with history of preterm labour. In our study this factor was statistically matched to avoid any bias. 
Original Research Article

Table-1: Distribution according to cervical length and term or preterm delivery in study and control group.

\begin{tabular}{|c|c|c|c|c|c|c|}
\hline \multirow{2}{*}{$\begin{array}{c}\text { Cervical length } \\
(\mathbf{m m})\end{array}$} & \multicolumn{3}{|c|}{ Study Group } & \multicolumn{3}{c|}{ Control Group } \\
\cline { 2 - 7 } & $\begin{array}{c}\text { Preterm } \\
\mathbf{n}(\%)\end{array}$ & $\begin{array}{c}\text { Term } \\
\mathbf{n}(\%)\end{array}$ & $\begin{array}{c}\text { Total } \\
\mathbf{n}(\%)\end{array}$ & $\begin{array}{c}\text { Preterm } \\
\mathbf{n}(\%)\end{array}$ & $\begin{array}{c}\text { Term } \\
\mathbf{n}(\%)\end{array}$ & $\begin{array}{c}\text { Total } \\
\mathbf{n}(\%)\end{array}$ \\
\hline $15-20 \mathrm{~mm}$ & $8(29.63)$ & $0(0.00)$ & $8(8.00)$ & $3(23.08)$ & $0(0.00)$ & $3(3.00)$ \\
\hline $21-26 \mathrm{~mm}$ & $12(44.44)$ & $18(24.66)$ & $30(30.00)$ & $8(61.54)$ & $7(8.05)$ & $15(15.00)$ \\
\hline $27-32 \mathrm{~mm}$ & $6(22.22)$ & $23(31.51)$ & $29(29.00)$ & $1(7.69)$ & $10(11.49)$ & $11(11.00)$ \\
\hline $33-38 \mathrm{~mm}$ & $1(3.70)$ & $23(21.51)$ & $24(24.00)$ & $1(7.69)$ & $31(35.63)$ & $32(32.00)$ \\
\hline $39-44 \mathrm{~mm}$ & $0(0.00)$ & $9(12.33)$ & $9(9.00)$ & $0(0.00)$ & $39(44.83)$ & $39(39.00)$ \\
\hline Total & $\mathbf{2 7}$ & $\mathbf{7 3}$ & $\mathbf{1 0 0}$ & $\mathbf{1 3}$ & $\mathbf{8 7}$ & $\mathbf{1 0 0}$ \\
& $\mathbf{( 2 7 . 0 0 )}$ & $\mathbf{( 7 3 . 0 0 )}$ & $\mathbf{( 1 0 0 . 0 0 )}$ & $\mathbf{( 1 0 0 . 0 0 )}$ & $\mathbf{( 1 0 0 . 0 0 )}$ & $\mathbf{( 1 0 0 . 0 0 )}$ \\
\hline
\end{tabular}

Table- 2: Mean \pm S.D. of cervical length of study and control group women who delivered preterm baby

\begin{tabular}{|c|c|c|}
\hline \multirow{2}{*}{ Cervical length } & \multicolumn{2}{|c|}{ Mean \pm SD } \\
\cline { 2 - 3 } & Study group & Control \\
\hline $15-20 \mathrm{~mm}$ & $17.50 \pm 1.00(\mathrm{n}=8)$ & $17.33 \pm 1.88(\mathrm{n}=3)$ \\
\hline $21-26 \mathrm{~mm}$ & $24.17 \pm 0.99(\mathrm{n}=12)$ & $25.00 \pm 1.00(\mathrm{n}=8)$ \\
\hline $27 \mathrm{~mm} \&$ above & $29.00 \pm 2.27(\mathrm{n}=1)$ & $32.00 \pm 2.00(\mathrm{n}=2)$ \\
\hline
\end{tabular}

Table-3: Predictive value, sensitivity and specificity for preterm delivery of transvaginal ultrasonography measurement of cervical length in study group and control group.

\begin{tabular}{|c|c|c|c|c|c|c|}
\hline \multicolumn{3}{|c|}{ Study Group } & \multicolumn{3}{c|}{ Control Group } \\
\hline \multirow{2}{*}{$\begin{array}{c}\text { Cervical length } \\
(\mathbf{m m})\end{array}$} & \multicolumn{2}{|c|}{ Delivery } & \multirow{2}{*}{ Total } & \multicolumn{2}{c|}{ Delivery } & \multirow{2}{*}{ Total } \\
\cline { 2 - 3 } & Preterm & Term & & Preterm & Term & \\
$\leq 26 \mathrm{~mm}$ & 20 & 18 & 38 & 11 & 7 & 82 \\
$\geq 26 \mathrm{~mm}$ & 7 & 55 & 62 & 2 & 80 & $\mathbf{1 0 0}$ \\
Total & $\mathbf{2 7}$ & $\mathbf{7 3}$ & $\mathbf{1 0 0}$ & $\mathbf{1 3}$ & $\mathbf{8 7}$ & $\mathbf{1 3}$
\end{tabular}

In study group $8(29.63 \%)$ had cervical length $15-20 \mathrm{~mm}$ and all patient delivered preterm. Cervical length measurement was 21-26 mm in $30(30 \%)$ women and among them 12 (44.44\%) delivered preterm. Cervical length measurement was 27-32 mm in $29(29 \%)$ women and among them $6(22.22 \%)$ delivered preterm. Remaining 33 patients had cervical length $33 \mathrm{~mm}$ and above. None of the women in $39 \mathrm{~mm}$ or above delivered preterm. In control group 15-20 mm cervical length was in 3 patients and none of them reached to term. Women who delivered preterm delivery $8(61.54 \%)$ had cervical length between $21-26$ $\mathrm{mm}$. The remaining 82 women had cervical length $27 \mathrm{~mm}$ or above and out of them only 2 delivered preterm. None of the women among $39 \mathrm{~mm}$ or above cervical length measurement delivered preterm. (Table-1)

To determine the most useful cutoff point for cervical length, we referred the study done by Rosenberg P et al 1997 [7]. This showed that a cutoff point of $26 \mathrm{~mm}$ best minimized both the false positive and false negative results.

In study group $38.00 \%$ women had cervical length $\leq 26 \mathrm{~mm}$ and out of them $20(74.07 \%)$ delivered preterm while cervical length $>26 \mathrm{~mm}$ found in $62.00 \%$ women, among them $55(75.34 \%)$ delivered at term only 7 delivered preterm. This was because there may be many etiological factors of preterm labour which may not be identified. In control group $13.00 \%$ delivered preterm and among preterm delivered women 11 had cervical length $\leq 26 \mathrm{~mm}$. 82 women had cervical length $>26$ $\mathrm{mm}$ and only $2(15.38 \%)$ out of them delivered preterm

Mean cervical length with standard deviation was $17.33 \pm 1.88 \mathrm{~mm}$ in 3 patients who had cervical length between $15-20 \mathrm{~mm}$ in control group while in study group it was $17.50 \pm 1.00 \mathrm{~mm}$ of 8 patients. Mean cervical length with standard deviation was $25.00 \pm 1.00 \mathrm{~mm}$ in 8 patients who had cervical length between 21-26 mm in control group while in study group it was $24.17 \pm 0.99 \mathrm{~mm}$ of 12 patients. Mean cervical length with standard deviation was $32.00 \pm 2.00 \mathrm{~mm}$ in 2 patients who had cervical length $\geq 27 \mathrm{~mm}$ in control group while in study group it was $29.00 \pm 2.27 \mathrm{~mm}$ of 1patient. (Table-2) 
Original Research Article

In study group 38 women had cervical length $\leq 26 \mathrm{~mm}$ remaining 62 had $\geq 26 \mathrm{~mm}$. 20 out of 38 and 7 out of 62 women delivered preterm so in study group 27 women delivered preterm. Risk of preterm delivery was $52.10 \%$ with abnormal result and $11.28 \%$ with normal result. In control group 18 women had cervical length $\leq 26 \mathrm{~mm}$ remaining 82 had $\geq 26 \mathrm{~mm}$. 11 out of 18 and 2 out of 82 women delivered preterm so in control group 13 women delivered preterm. Risk of preterm delivery was $61.12 \%$ with abnormal result and $2.43 \%$ with normal result.

In control group 17 babies were low birth weight (Weight $<2.5 \mathrm{~kg}$ ), 11(64.70\%) babies were from these women whose cervical length was $<26 \mathrm{~mm}$ and in study group 31 babies were LBW. 23(74.19\%) out of them were from those women whose cervical length was $\leq 26 \mathrm{~mm}$. Mean birth weight of preterm babies was $1.72 \pm 0.18 \mathrm{~kg}$ in control group and $1.71 \pm 0.13 \mathrm{~kg}$ in study group. There was no significant difference between 2 group for birth weight of preterm and term baby as mean birth weight of term babies was $2.69 \pm 0.22$ in control group and $2.60 \pm 0.23$ in case group. ( $p$ value $>0.05$ )

Mean birth weight was $1.47 \pm 0.14$ in control group and $1.54 \pm 0.07$ in study group in which cervical length was between $15-20$ $\mathrm{mm}$. Mean birth weight was $1.75 \pm 0.04$ in control group and $1.75 \pm 0.06$ in study group in which cervical length was between 21-26 mm. Mean birth weight was $1.97 \pm 0.03$ in control group and $1.84 \pm 0.08$ in study group in which cervical length was $\geq 27$ mm. (p value $>0.05)$

In our Study Group, Prevalence - 27\%, Positive predictive value $-52.10 \%$, Negative predictive value $-88.70 \%$, Sensitivity $81.48 \%$, Specificity $-75.34 \%$ and in control group Prevalence $-13 \%$, Positive predictive value $-62.12 \%$, Negative predictive value $-97.56 \%$, Sensitivity-91.53\%, Specificity - $91.95 \%$ wereobserved.( Table- 3)

\section{Discussion}

In our study $80 \%$ of control group and $81 \%$ of study group were in age group of $20-25$ years, $12 \%$ of control group and $11 \%$ of study group were in age group of 26-30 years. Statistically mean age of participants were 21.98 years and standard deviation 3.0739. In a similar study doneby Kore SJetal 2009 majority of the women were in age group of 20-30 years and mean age of the subjects studied was 23 years [8]. A study done by Qudah S et al 2017 in Jordan on 100 patients also showed similar results [9]. An Indian study done on 91 pregnant patients by Khushboo et al 2017 had $86.8 \%$ patients in this age group [10]. Relatively young women participated in the study as age was statistically matched factor, age distribution was not significantly different between both group.

About 39 women in control group and 36 women in study group were primigravida, remaining were multigravida. In an Indian study done by Begum J et al 2014 studied 51 cases, out of them $22(43.20 \%)$ were primigravida and 29 cases $(56.80 \%)$ were multigravida [11]. A study done by QudahS et al 2017 in Jordan on 100 women including $38.75 \%$ were primi and $61.25 \%$ were multiparous [9].

History of preterm labor was present in 27 women in study group and 28 women in control group. About 20 $(74.07 \%$ ) out of 27 had cervical length $\leq 26 \mathrm{~mm}$ in study group and 7 (25\%) women in control group had cervical length $\leq 26 \mathrm{~mm}$ as it is known that preterm labour is more common in patient with history of preterm labor. In our study this factor was statistically matched to avoid any bias. A study done by Qudah S et al 2017 in Jordanon 100 women had incidence of preterm delivery $90 \%$ with cervical length $<30 \mathrm{~mm}$. Mean cervical length with standard deviation was $17.33 \pm 1.88 \mathrm{~mm}$ in 3 patients who had cervical length between $15-20 \mathrm{~mm}$ in control group while in study group it was $17.50 \pm 1.00 \mathrm{~mm}$ of 8 patients. Mean cervical length with standard deviation was $25.00 \pm 1.00 \mathrm{~mm}$ in 8 patients who had cervical length between 21-26 $\mathrm{mm}$ in control group while in study group it was $24.17 \pm 0.99 \mathrm{~mm}$ of 12 patients. Mean cervical length with standard deviation was $32.00 \pm 2.00 \mathrm{~mm}$ in 2 patients who had cervical length $\geq 27 \mathrm{~mm}$ in control group while in study group it was $29.00 \pm 2.27 \mathrm{~mm}$ of 1 patient.A study done by Qudah S et al 2017 in Jordanon 100 women had mean cervical length $21 \pm 5 \mathrm{~mm}$ with cervical length $<30 \mathrm{~mm}[9]$. In an Indian study done by khushboo et al 2017 had mean cervical length at 30 weeks $28.1 \pm 3.9 \mathrm{~mm}$. Iams JD et al[12], Mukherji J et al[13], Berghella $\mathrm{V}$ et al 1997 [14]. A study done on 100 patients by Wadhawan UT et al 2017 had mean cervical length $33.7 \mathrm{~mm}$ [15]. The large cervical length in the studies compared to present study could be due to different racial profile and exclusion of subjects at higher base line risk of preterm delivery.

In study group 38 women had cervical length $\leq 26 \mathrm{~mm}$ remaining 62 had $\geq 26 \mathrm{~mm}$. 20 out of 38 and 7 out of 62 women delivered preterm so in study group 27 women delivered preterm. Risk of preterm delivery was $52.10 \%$ with abnormal result and $11.28 \%$ with normal result. In control group 18 women had cervical length $\leq 26 \mathrm{~mm}$ remaining 82 had $\geq 26 \mathrm{~mm}$. 11 out of 18 and 2 out of 82 women delivered preterm so in control group 13 women 
delivered preterm. Risk of preterm delivery was $61.12 \%$ with abnormal result and $2.43 \%$ with normal result. A study done by Qudah S et al 2017 in Jordanon 100 women had incidence of preterm delivery $90 \%$ with cervical length $<30 \mathrm{~mm}$. Rosenberg et al 1997 showed risk of preterm labour with abnormal results was $50 \%$ and with normal test results was $10.9 \%$ (7). A study done by Crane JM et al 1997 showed that risk of preterm was greater in patients who showed shortening of upper cervical segment $<10 \mathrm{~mm}$ [16].

In control group 17 babies were low birth weight (Weight $<2.5 \mathrm{~kg}), 11(64.70 \%)$ babies were from these women whose cervical length was $<26 \mathrm{~mm}$ and in study group 31 babies were LBW. $23(74.19 \%)$ out of them were from those women whose cervical length was $\leq 26 \mathrm{~mm}$. Mean birth weight of preterm babies was $1.72 \pm 0.18 \mathrm{~kg}$ in control group and $1.71 \pm 0.13 \mathrm{~kg}$ in study group. There was no significant difference between 2 group for birth weight of preterm and term baby as mean birth weight of term babies was $2.69 \pm 0.22$ in control group and $2.60 \pm 0.23$ in case group. In an Indian study done on 100 patients by WadhawanUT et al 2017 had mean birthweight $2.7 \mathrm{~kg}$ [15].

In our study in study group revealed Prevalence $-27 \%$, Positive predictive value $-52.10 \%$, Negative predictive value $-88.70 \%$, Sensitivity - $81.48 \%$, Specificity $75.34 \%$. Similar studies conducted by Begum J et al 2014 andIams JD et al1996 showed similar results $(11,12)$.

Tsoi E et al 2003 studied 216 patients showed similar results as our study (1). These results showed that TVS had excellent negative predictive value so its use in high risk for preterm labour cases is justified and in asymptomatic cases it also had a good result.

\section{Conclusion}

The study therefore concludes that the risk of preterm delivery is high in women with cervical length $\leq 26 \mathrm{~mm}$ and strict management is required for those cervical length is less than $20 \mathrm{~mm}$ to improve the neonatal outcome. We found that TVS had good sensivity, specificity, predictive value in both group. Thus measurement of cervical length by TVS can be used to predict increase risk of preterm delivery cases with threatened preterm labor.

A positive correlation was observed between cervical length and birth weight of preterm baby. Preventive measures can be carried out and this may allow reduction in number of unnecessary potentially dangerous tocolytic treatment and hospitalization. Its use in asymptomatic women need large clinical trial.

Obsgyne Review: Journal of Obstetrics and Gynecology

\section{Abbreviations}

Original Research Article

TVS- Transvaginal Sonography, IUGR- Intrauterine growth retardation, PPV- Positive predictive value, NPVNegative predictive value, LBW- Low birth weight.

Funding: Nil, Conflict of interest: Nil Permission from IRB: Yes

\section{References}

1. Tsoi E, Akmal S, Rane S, Otigbah C, Nicolaides KH. Ultrasound assessment of cervical length in threatened preterm labor. Ultrasound Obstet Gynecol. 2003 Jun; 21 (6): 552-5.

2. Kurpa FG, Faltin D, Cecatti JG, Surita FGC, Souza JP. Predictors of preterm birth. Int J Gynecol Obstet. 2006; 94:5-11.

3. Yoshizato T, Obama H, Nojiri T, Miyaka.Y, Miyamoto $\mathrm{S}$, Kawarabayashi T. Clinical significance of cervical length shortening before 31 week's gestation assessed by longitudinal observation using transvaginal ultrasonography. J Obstet Gynaecol. Res. 2008;34:805-11.

4. Masamoto H, Nagai Y, Inamine M. et al. Outcome of pregnancy after laser conization: implications for infection as a causal link with preterm birth. J Obstet Gynaecol Res. 2008;34:838-842.

5. Lim K, Butt K, Crane JM. Diagnostic imaging committee; family physicians advisory committee; maternal fetal medicine committee. SOGC Clinical Practice Guideline. Ultra sonographic cervicalleng thassessment in predicting preterm birth in singletonpregnancies. J Obstet Gynaecol Can. 2011 May; 33 (5): 486-499. doi: 10. 1016/S1701-2163 (16) 34884-8.

6. Melamed N, Hiersch L, Domniz N, Maresky A, Bardin R, Yogev Y. Predictive value of cervical length in women with threatened preterm labor. Obstet Gynecol. 2013 Dec; 122 (6): 1279-87. doi: 10.1097/AOG.00000000000 00022 .

7. Rozenberg P, Goffinet F, Kayem G, Perdu M, Phillipoe HJ, Misand J. The value of intravaginal ultrasonography of the cervix uteri for evaluation of the risk of premature labour. Jr de Gynecologic Obstetrics et biologic de la Reproduction.1997; 26 (6):623-29.

8. Kore SJ, Parikh MP, Lakhotia, Kulkarni, Ambiye VR. Prediction of risk of preterm delivery by cervical assessment by transvaginal ultrasonography. J Obstet Gynecol India. 2009;59(2):131-35.

Available online at : www.medresearch.in 42 | P a g e 
9. Qudah S, Athamneh T, Tawlbeh A, Daklallah L, Alhajji M. Cervical length as a predictor risk of preterm delivery. Journal of Royal Medical services. 2017 March; 24(1):18-21.

10. Khusboo, K Dinesh, Verma A, Chaursia S, Nag R. Cervical sonomorphometric evaluation of normal and preterm labour by transvaginal and transabdominal sonography. Int J Reprod Contracept Obstet gynecol.2017 Feb;6(2):417-422.

11. Begum J, Behera AK. Cervical length by ultrasound as a predictor of preterm labour. Int J Reprod Contracept Obstet gynecol.2014 Sept;3(3):646-652.

12. Iams JD, Goldenberg RL, Meis PJ, Mercer BM, Moawad A, Das A, Thom E, McNellis D, Copper RL, Johnson F, Roberts JM. The length of the cervix and the risk ofspontaneouspremature delivery. National Institute of Child Health and Human Development Maternal Fetal Medicine Unit Network. NEng1 J Med. 1996 Feb 29;334 (9):567-72.

\section{Original Research Article}

13. Mukherji J, Anant M, Ghosh S, Bhattacharyya SK, Hazra A, Kamilya GS. Normative data of cervical length in singleton pregnancy in women attending a tertiary care hospital in eastern India. Indian J Med Res. 2011;133 (5): 492-6.

14. Berghella V, TolosaJE,Kuhlman K, Welner S, Bolognese RJ, Wepner RJ. Cervical ultrasonography compared with manual examination as predictor of preterm delivery. Am. J. Obstetrics and gynaecology. 1997 Oct.; 177(4):723-30.

15. Wadhawan UT, Shah NP, Patil AN. Prediction of cervical length by cervical length. Int J Reprod Contracept Obstet gynecol.2017 July; 6(7):2978-2982.

16. Crane JM, Van den Hof M, Armson BA, Liston R. Transvaginalultrasound in the prediction of preterm delivery: singleton and twingestations.Obstet Gynecol. 1997 Sep;90(3):357-63.

\section{How to cite this article?}

Verma S, Meena B. S, Pooja, Sehra R. N. A study of cervical length measured ultrasonographically in prediction of preterm delivery. Obs Rev:J obstet Gynecol 2017;3(4):38-43.doi:10.17511/joog.2017.i04.02. 